\title{
The Hippocampus Plays an Important Role in Eyeblink Conditioning with a Short Trace Interval in Glutamate Receptor Subunit $\delta 2$ Mutant Mice
}

\author{
Kanako Takatsuki, ${ }^{1}$ Shigenori Kawahara, ${ }^{1,3}$ Sadaharu Kotani, ${ }^{1}$ Satoshi Fukunaga, ${ }^{1}$ Hisashi Mori, ${ }^{2}$ Masayoshi Mishina, ${ }^{2}$ \\ and Yutaka Kirino ${ }^{1}$ \\ ${ }^{1}$ Laboratory of Neurobiophysics, School of Pharmaceutical Sciences, The University of Tokyo, Tokyo 113-0033, Japan, ${ }^{2}$ Department of Molecular \\ Neurobiology and Pharmacology, Graduate School of Medicine, The University of Tokyo, and Solution Oriented Research for Science and Technology, \\ Japan Science and Technology Corporation, Tokyo 113-0033, Japan, and ${ }^{3}$ Core Research for Evolutional Science and Technology, Japan Science and \\ Technology Corporation, Saitama 332-0012, Japan
}

Mutant mice lacking the glutamate receptor subunit $\delta 2$ exhibit changes in the structure and function of the cerebellar cortex. The most prominent functional feature is a deficiency in the long-term depression (LTD) at parallel fiber-Purkinje cell synapses. These mutant mice exhibit severe impairment during delay eyeblink conditioning but learn normally during trace eyeblink conditioning without the cerebellar LTD, even with a 0 trace interval. We investigated the hippocampal contribution to this cerebellar LTD-independent " 0 trace interval" learning. The mutant mice whose dorsal hippocampi were aspirated exhibited severe impairment in learning, whereas those that received post-training hippocampal lesions retained the memory. The wild-type mice showed no impairment in either case. These results suggest that the hippocampal component of the eyeblink conditioning task becomes dominant when cerebellar LTD is impaired.

Key words: classical conditioning; eyeblink; hippocampus; cerebellum; long-term depression; mouse

\section{Introduction}

The hippocampus is involved in various kinds of learning (Morris et al., 1982; Barnes, 1988). Although its role could be interpreted in terms of behavioral function, the exact mechanism to execute that function remains to be elucidated. To achieve this understanding, knowledge about the neural network, with which the hippocampus interacts, is critical. Classical eyeblink conditioning is one of candidates from which such knowledge could be obtained. In this learning, the essential neural circuit has been studied extensively with a delay paradigm, in which the unconditioned stimulus (US) is delayed and coterminates with the conditioned stimulus (CS). Thompson and colleagues have indicated that the locus of the memory trace is in the cerebellum; they stress the importance for memory function of long-term depression (LTD) at parallel fiber (PF)-Purkinje cell (PC) synapses, as well as the presumptive plasticity in the interpositus nucleus (Kim and Thompson, 1997). The contribution of the hippocampus to eyeblink conditioning has been shown to differ across conditioning paradigms. For example, an intact hippocampus is required

Received April 16, 2002; revised Sept. 3, 2002; accepted 0ct. 9, 2002.

This work was supported by Ministry of Education, Culture, Sports, Science and Technology of Japan Grants-inAid 13210036 and 13680734 and a grant from the Core Research for Evolution Science and Technology of Japan Science and Technology Corporation.

Correspondence should be addressed to Shigenori Kawahara, Laboratory of Neurobiophysics, School of Pharmaceutical Sciences, The University of Tokyo, 7-3-1 Hongo, Bunkyo-ku, Tokyo 113-0033, Japan. E-mail: kawahara@mol.f.u-tokyo.ac.jp.

Copyright $\odot 2002$ Society for Neuroscience $\quad 0270-6474 / 02 / 220017-06 \$ 15.00 / 0$ for successful learning in trace conditioning (Solomon et al., 1986; Moyer et al., 1990) and discrimination reversal conditioning (Berger and Orr, 1983) but not in delay conditioning (Solomon et al., 1986).

We investigated previously classical eyeblink conditioning in mutant mice lacking the glutamate receptor subunit $\delta 2$ (GluR $\delta 2$ ). These mutant mice exhibit a selective dysfunction of the cerebellar cortex, impaired cerebellar LTD (Kashiwabuchi et al., 1995), a decrease in the number of PF-PC synapses (Kurihara et al., 1997), and multiple innervation of PCs by climbing fibers (Kashiwabuchi et al., 1995). Consistent with the hypothesis that cerebellar LTD plays a critical role in eyeblink conditioning (Ito, 1989; Thompson and Kim, 1996), GluR $\delta 2^{-/-}$mice exhibited severe impairment in learning when a delay paradigm was used (Kishimoto et al., 2001a). However, GluR $\delta 2^{-1-}$ mice learned normally in the trace paradigm, in which a stimulus-free trace interval intervenes between the CS and US (Kishimoto et al., 2001a), and even in a "trace 0 paradigm," in which the US starts just after the CS ends (Kishimoto et al., 2001c). These results suggest that another learning mechanism, one that does not require cerebellar LTD, underlies the ability of GluR $\delta 2^{-/-}$mice to learn in eyeblink conditioning paradigms in which the US does not overlap with the CS. Results in another cerebellar LTD-deficient mouse lacking the phospholipase $\mathrm{C} \beta 4$ subunit also support this hypothesis (Kishimoto et al., 2001b). Furthermore, we found recently that scopolamine impairs cerebellar LTD-independent learning in GluR $\delta 2^{-1-}$ mice (Takatsuki et al., 2002). This sug- 
gests that the hippocampus contributes to LTD-independent learning, because scopolamine slows delay eyeblink conditioning primarily through its effect on the hippocampus (Solomon et al., 1983) via the septum (Solomon and Gottfried, 1981); scopolamine also impairs trace eyeblink conditioning, which we know requires an intact hippocampus (Kaneko and Thompson, 1997). To examine the hippocampal contribution to cerebellar LTDindependent learning, we investigated the effect of hippocampal lesions on learning using a trace 0 paradigm with GluR $\delta 2^{-/-}$ mice.

\section{Materials and Methods}

Subjects and surgery. We used GluR $\delta 2^{-1-}$ mice with a 99.99\% C57BL/6 genetic background (Kishimoto et al., 2001a) and wild-type C57BL/6 mice (Japan SLC, Hamamatsu, Shizuoka, Japan). The animals were kept on a $12 \mathrm{hr}$ light/dark cycle with ad libitum access to food and water. All experiments were performed in accordance with the guidelines established by the Institutional Animal Investigation Committee at the University of Tokyo and the National Institutes of Health Guide for the Care and Use of Laboratory Animals. Before surgery, the animals were anesthetized with ketamine ( $80 \mathrm{mg} / \mathrm{kg}$, i.p.; Sankyo, Tokyo, Japan) and xylazine (20 mg/kg, i.p.; Bayer, Tokyo, Japan). A bilateral aspiration of the dorsal hippocampus and overlying neocortex was performed on the hippocampal lesion group. The control group received only bilateral aspiration of the neocortex. Four Teflon-coated stainless steel wires (\#7910; A-M Systems, Carlsborg, WA) were implanted to record electromyographic (EMG) activity and to deliver a periorbital shock, as described in our previous report (Kishimoto et al., 2001a).

Behavioral training. At least $3 \mathrm{~d}$ after implanting the electrodes, the animals were given $2 \mathrm{~d}$ to adapt to the experimental apparatus, during which EMGs were recorded to calculate spontaneous eyeblink frequency. The conditioning began the next day. Daily conditioning consisted of 90 CS-US paired trials and 10 CS-alone trials on every 10th trial, with a pseudorandomized intertrial interval of $20-40 \mathrm{sec}$. In the paired trials, a 352 msec tone CS ( $1 \mathrm{kHz}, 90 \mathrm{~dB}$ ) was followed by a $100 \mathrm{msec}$ periorbital shock US (100 Hz square pulses). The US intensity was carefully calibrated to elicit an eyeblink-head-turn response and adjusted daily for each animal; it ranged from 8 to $17 \mathrm{~V}$ (Kishimoto et al., 2001a). The interstimulus interval was set at $352 \mathrm{msec}$ so that the trace interval was $0 \mathrm{msec}$.

Data analysis. The conditioned response (CR) was monitored through eyelid EMG activity, and the analysis of that activity was performed as described previously (Kishimoto et al., 2001a). In brief, mean + SD of the amplitudes of the EMG activity for $300 \mathrm{msec}$ before CS onset in 100 trials was defined as the threshold, which was then used in the analysis below. In each trial, average values of EMG amplitude above the threshold were calculated for $300 \mathrm{msec}$ before CS onset (pre-value), $30 \mathrm{msec}$ after CS onset (startle-value), and $202 \mathrm{msec}$ before US onset (CR-value). If both the pre-value and startle-value were $<10 \%$ of threshold, the trial was regarded as a valid trial. Among the valid trials, a trial was assumed to contain the CR if the CR value was larger than $1 \%$ of threshold and it exceeded two times the pre-value. For the CS-alone trials, the period for CR-value calculation was extended to the CS end. To evaluate the effect on the startle response, we calculated the frequency of trials in which the startle-value exceeded $10 \%$ of threshold. The frequency of CRs in the valid trials $(\mathrm{CR} \%)$ was expressed as mean \pm SEM. Statistical significance was determined by a two-way ANOVA and a three-way repeatedmeasures ANOVA using SPSS (Chicago, IL) statistical software. $p<0.05$ was considered significant in this study.

Experimental protocols. In acquisition experiments, mice first received the lesion, electrodes were implanted after a recovery period of $10 \mathrm{~d}$, and then conditioning occurred for $7 \mathrm{~d}$ for CR acquisition. In the retention experiments, the order was electrode implanting, acquisition sessions, and then lesion. Mice for which CR\% reached the criteria described below were divided randomly into two groups and received a cortical lesion or a hippocampal lesion on the next day. After a recovery period of 2 weeks, all mice underwent $7 \mathrm{~d}$ of retention testing (CS-US paired session). In retention experiment 1 , mice underwent $7 \mathrm{~d}$ of acquisition session. We used only those mice whose CR\% exceeded $50 \%$ on the seventh day of the acquisition session. In retention experiment 2 , mice were conditioned until their CR\% exceeded $70 \%$. The mice that did not reach this criterion after $14 \mathrm{~d}$ of acquisition session were excluded from additional study.

Histology. After completing all behavioral experiments, the mice were overdosed with sodium pentobarbital and perfused transcardially with $0.9 \%$ saline, followed by $10 \%$ Formalin. Brains were removed and placed in $10 \%$ Formalin. Before sectioning, brains were placed in a $30 \%$ sucrose solution overnight. Frozen sections ( $40 \mu \mathrm{m}$ thick) were made using a cryostat and stained with cresyl violet. The largest and smallest lesioned areas were reconstructed from the sections according to the stereotaxic atlas of the mouse brain (Paxinos and Franklin, 2001).
A

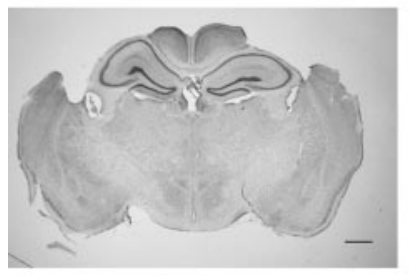

C

$-0.94$

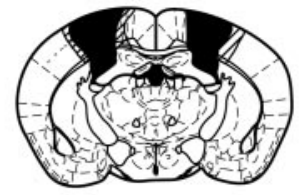

$-1.46$

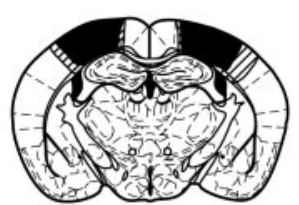

$-1.94$

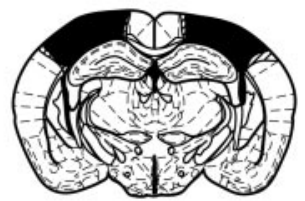

$-2.46$

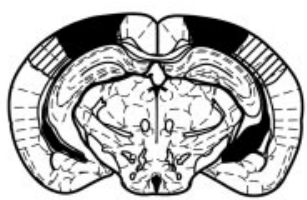

$-2.92$

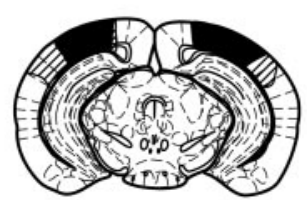

B

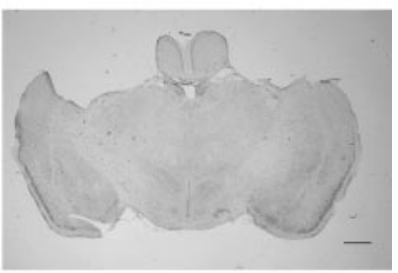

D
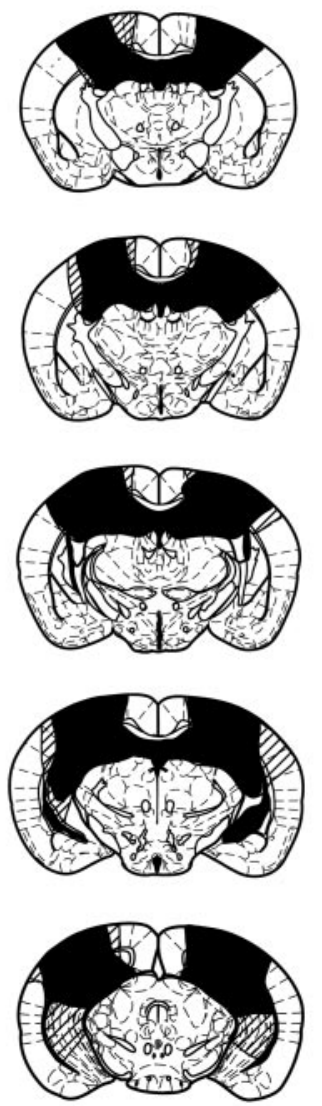

Figure 1. Extent of hippocampal lesion. $A, B$, Typical brain sections from the control group $(A)$ and the hippocampal-lesion group $(B)$. Sections of $40 \mu \mathrm{m}$ were stained with cresyl violet. Scale bars, $1 \mathrm{~mm}$. C, D, Histological reconstruction of the control group $(C)$ and the hippocampal-lesion group $(D)$. The filled and shaded areas indicate the least and the most extensive lesions, respectively. Numbers on the left indicate stereotaxic coordinates (in millimeters) relative to bregma. 

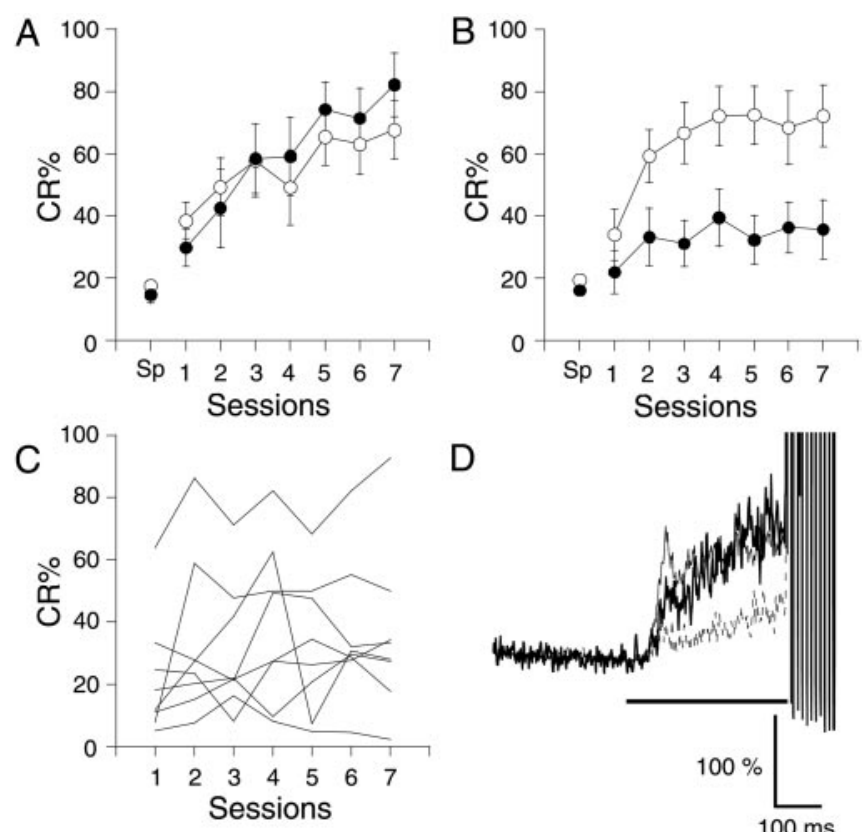

D

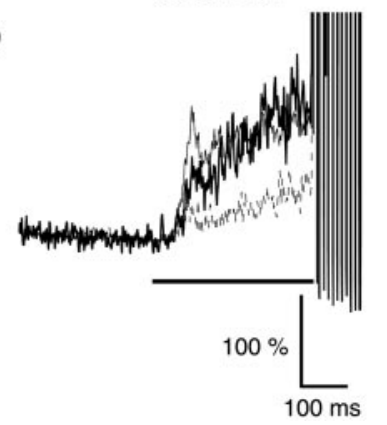

Figure 2. Effect of hippocampal lesions made before conditioning. $A, B, C R \%$ in wild-type $(A)$ and GluR $\delta 2^{-1-}(B)$ mice. These mice received a bilateral aspiration of the dorsal hippocampus and the overlying neocortex (hippocampal-lesion; filled circles; $n=7$ for wild-type mice and $n=8$ for mutant mice) or only the overlying neocortex (cortical-lesion; open circles; $n=8$ for wild-type mice and $n=9$ for mutant mice). C, CR\% of the individual mice in the hippocampal-lesioned GluR $\delta 2^{-1-}$ sample. Each line represents the CR\% of the individual mice. $D$, Temporal pattern of the CR in GluR $\delta 2^{-1-}$ mice. The EMG amplitude data in the last session were averaged and normalized by the activities before the $\mathrm{CS}$ in $\mathrm{GluR} \delta 2^{-1-}$ mice. The thin, thick, and dotted traces represent the control group, learned hippocampal-lesioned group, and nonlearned hippocampal-lesioned group, respectively. The horizontal lines at the bottom indicate the timing of the CS.

\section{Results}

Histology

To confirm the extent of each lesion, coronal sections (40 $\mu \mathrm{m}$ thick) were made through the length of the hippocampus after conclusion of the behavioral experiments. We completely removed the dorsal hippocampus in all mice in the hippocampallesion group (Fig. $1 \mathrm{~B}$ ). Although some of them retained the posteroventral portion of the hippocampus, the fimbria was bilaterally transected so that the remaining ventral hippocampus was isolated from the fornix. There was no damage to surrounding structures, such as the amygdala, thalamus, or entorhinal cortex, except the overlying neocortex. The results of the histological analysis are summarized in Figure 1, $C$ and $D$.

\footnotetext{
Acquisition of the CR depends primarily on the hippocampus in GluR $\delta 2$ mutant mice

When conditioned using a trace 0 paradigm, the hippocampallesioned GluR $\delta 2^{-l-}$ mice exhibited severe learning impairment compared with the cortical-lesioned GluR $\delta 2^{-1-}$ mice (Fig. $2 B$ ). In contrast, the hippocampal-lesioned wild-type mice learned as normally as the control wild-type mice did (Fig. 2A). A three-way repeated-measures ANOVA revealed that there was a significant effect for lesion type $\left(F_{(1,203)}=14.645 ; p<0.001\right)$ and for genotype $\left(F_{(1,203)}=4.891 ; p<0.05\right)$, indicating that the learning impairment attributable to a hippocampal lesion differed between wild-type and GluR $\delta 2^{-1-}$ mice. There was no significant effect of interactions between sessions and lesion type $\left(F_{(6,203)}=\right.$ $0.089 ; p>0.9)$ or between sessions and genotype $\left(F_{(6,203)}=\right.$ $0.708 ; p>0.6)$.
}
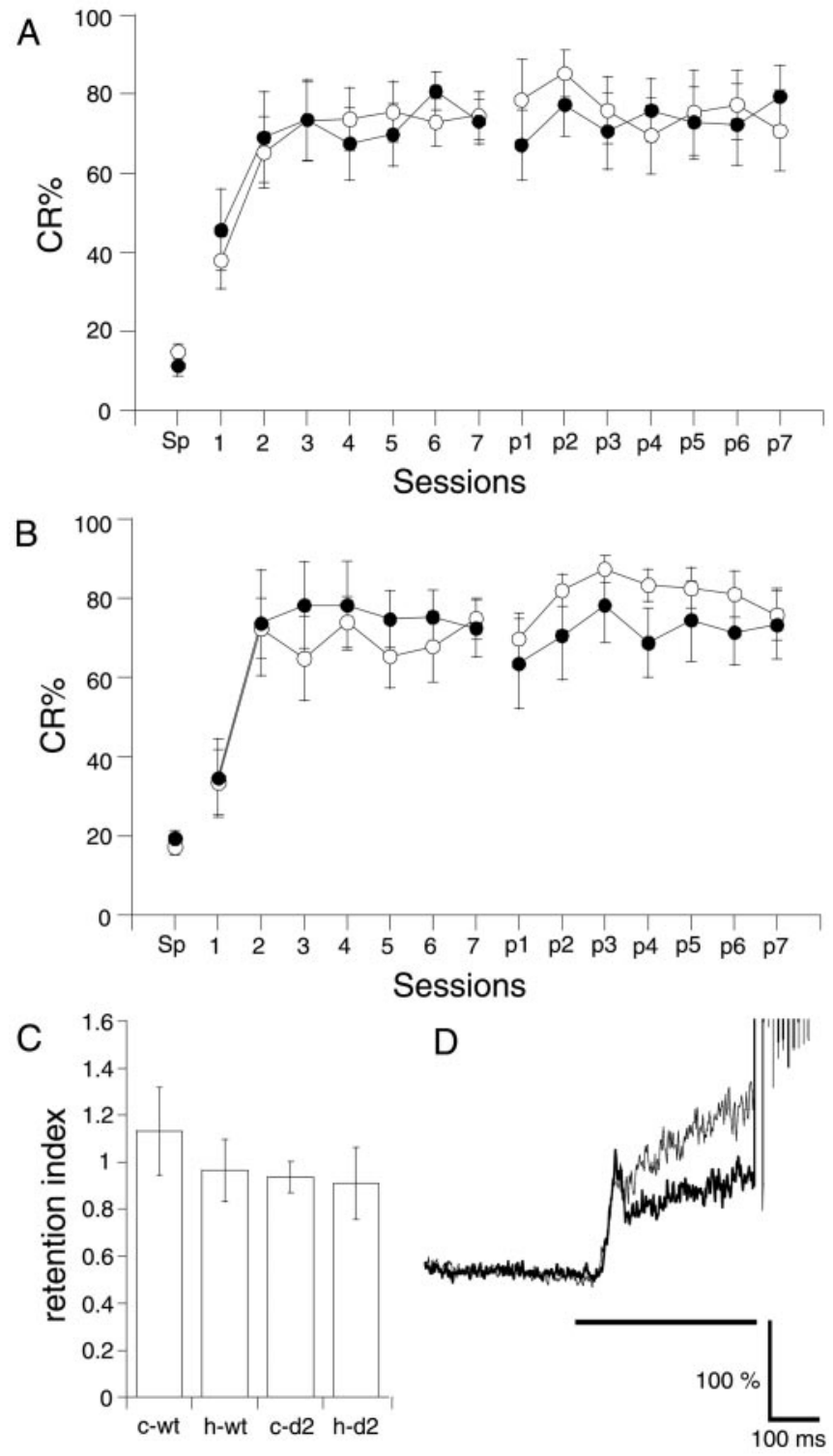

Figure 3. Effect of hippocampal lesions made after $7 \mathrm{~d}$ of conditioning. $A, B, C R \%$ in wildtype $(A)$ and GluR $\delta 2^{-1-}(B)$ mice. Mice were conditioned using a trace 0 paradigm for $7 \mathrm{~d}$ $(1-7)$ and then on the next day received a hippocampal lesion ( filled circles; $n=8$ for wildtype mice and $n=7$ for mutant mice) or a cortical lesion (open circles; $n=8$ for wild-type mice and $n=8$ for mutant mice). After 2 weeks of recovery, the mice were conditioned again for an additional $7 \mathrm{~d}$ ( $p 1-p 7)$. C, Retention index of the CR after the lesion. The ratio of the CR\% in the first postlesion session to that in the last prelesion session was calculated for wild-type mice $(w t)$ and for mutant mice (d2). c and $h$ refer to cortical lesion and hippocampal lesion, respectively. D, The temporal pattern of the CR in the first postlesion session of GluR $\delta 2^{-1-}$ mice. The thin and thick traces represent the control group and hippocampal-lesioned group, respectively.

Although most of the hippocampal-lesioned GluR $\delta 2^{-1-}$ mice exhibited severe learning impairment, two of them learned well, resulting in a smaller increase of CR\% on average. The CR\% reached $\sim 90 \%$ in one mouse and $50 \%$ in another mouse by the end of training and stayed almost at spontaneous levels in the remaining six mice (Fig. 2C). The extent of the hippocampal lesion in these two learned mice was intermediate, showing no correlation with their $\mathrm{CR} \%$. To investigate the temporal pattern of the EMG activities of these mice, the amplitude data of the valid trials in the last session were averaged in each mouse and then over the mice. Therefore, the pattern does not depend on the criterion used for CR detection. Consistent with their CR\%, the 

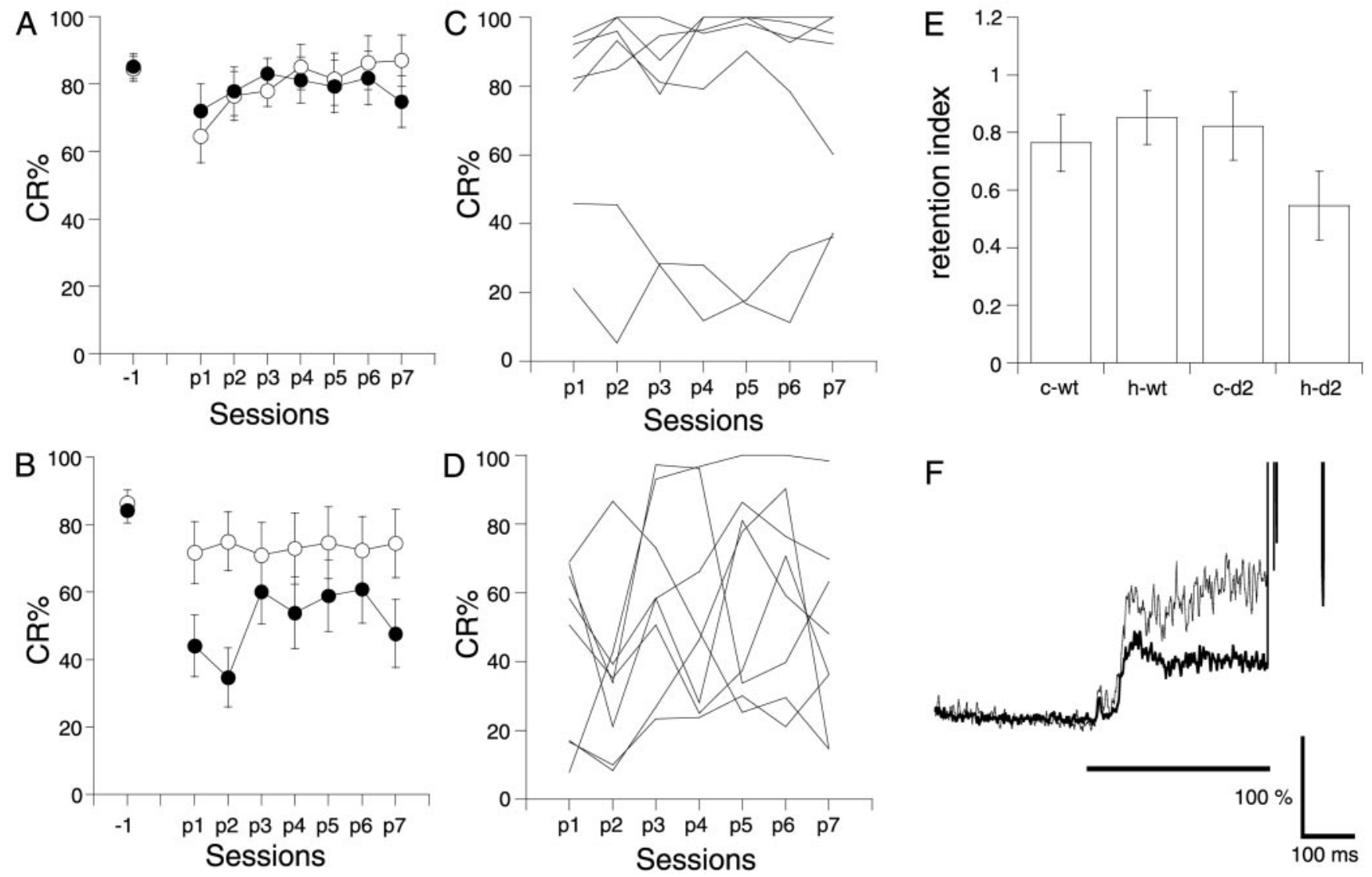

Figure 4. Effect of hippocampal lesions made immediately after conditioning. $A, B, C R \%$ in wild-type $(A)$ and GluR $\delta 2^{-1-}(B)$ mice. Mice were conditioned until their CR\% exceeded $70 \%$ and on the next day received a hippocampal lesion ( filled circle; $n=9$ for wild-type mice and $n=8$ for mutant mice) or a cortical lesion (open circle; $n=8$ for wild-type mice and $n=7$ for mutant mice). -1 and $p 1-p 7$ represent the last prelesion session and the postlesion sessions, respectively. C, D, CR\% of the individual mice in the cortical-lesioned GluR $\delta 2^{-1-}$ mice $(C)$ and hippocampal-lesioned GluR $\delta 2^{-1-}$ mice $(D)$. Each line represents the $C R \%$ of the individual mice. $E$, Retention index (see Fig. $3 C$ ) of the $C R$ after the lesion. c and $h$ refer to cortical lesion and hippocampal lesion, respectively. F, The temporal pattern of the CR in the first postlesion session of GluR $\delta 2^{-I-}$ mice. The thin and thick traces represent the control group and hippocampal-lesioned group, respectively.

amplitude of the average EMG activities of the six nonlearned hippocampal-lesioned GluR $\delta 2^{-1-}$ mice was small, whereas that of the two learned mice was similar to that of the control mice (Fig. 2D). The temporal pattern of the EMG activities was not noticeably changed in either groups, which is consistent with the previous results with this line of mutant mice (Kishimoto et al., 2001a,c).

\section{Retention experiment 1: the hippocampus is not essential for retention of the CR in GluR $\delta 2$ mutant mice}

Next, we tested whether the hippocampus was required for retention of the CR. In this experiment, mice received the lesion after $7 \mathrm{~d}$ of acquisition sessions. Eighteen of 28 wild-type mice and 20 of 31 GluR $\delta 2^{-1-}$ mice reached the criterion (see Materials and Methods). Their CR\% at the last acquisition session was $73.4 \pm$ 3.9 and $73.6 \pm 4.2 \%$, respectively. Even after removing the hippocampus and the overlying cortex, the $\mathrm{CR}$ remained at the same level as before, in both wild-type mice (Fig. $3 A$ ) and GluR $\delta 2^{-1-}$ mice (Fig. $3 B$ ). A three-way repeated-measures ANOVA revealed that the CR\% of the postlesion sessions was not significantly influenced by lesion type $\left(F_{(1,196)}=3.103 ; p>0.05\right)$ or by genotype $\left(F_{(1,196)}=0.131 ; p>0.7\right)$, indicating that the hippocampus is not necessary for retention of the CR in either GluR $\delta 2^{-1-}$ mice or the wild-type mice. Figure $3 C$ shows the retention index of the $\mathrm{CR}$, calculated by dividing the $\mathrm{CR} \%$ in the first postlesion session by the CR\% in the last prelesion session. A two-way ANOVA revealed that there was no significant effect for either lesion type $\left(F_{(1,27)}=0.477 ; p>0.4\right)$ or genotype $\left(F_{(1,27)}=\right.$ $0.793 ; p>0.3)$. The average temporal pattern of the EMG activities in the first postlesion session of the hippocampallesioned GluR $\delta 2^{-1-}$ mice was also almost the same as that of the control mutant mice (Fig. 3D).

\section{Retention experiment 2: the hippocampus is partially involved for retention or expression of the CR right after reaching asymptotic level}

The retention experiment 1 indicated that the hippocampus is not essential for retention of the CR a few days after reaching asymptotic level. In this experiment, we examined the contribution of the hippocampus in an early phase of the asymptotic state of memory. Mice received the lesion on the next day after their CR\% exceeded $70 \%$. Seventeen of 20 wild-type mice and 18 of 22 GluR $\delta 2^{-/-}$mice reached the criterion. Their CR\% in the last session and the number of days conditioned were $84.9 \pm 2.2 \%$ and $3.4 \pm 0.5 \mathrm{~d}$ in the wild-type mice and $85.4 \pm 2.5 \%$ and $5.1 \pm$ $0.9 \mathrm{~d}$ in the GluR $\delta 2^{-1-}$ mice. They were assigned randomly to the lesion groups.

In the wild-type mice, the hippocampal-lesion group retained the memory as well as the control group (Fig. $4 A$ ). In GluR $\delta 2^{-1-}$ mice, the hippocampal-lesion group exhibited moderate impairment in retention of the CR compared with the cortical-lesion group (Fig. 4B). Among the eight hippocampal-lesioned GluR $\delta 2^{-1-}$ mice, five mice retained the CR well, whereas the other three mice showed severe impairment, although two of the 
latter three mice showed an increase in CR\% during the subsequent conditioning (Fig. 4D). Among seven cortical-lesioned GluR $\delta 2^{-/-}$mice, five mice retained the CR well, whereas the other two mice showed impairment (Fig. 4C). A two-way ANOVA on the retention index (Fig. $4 E$ ) revealed that there was no significant effect for lesion type $\left(F_{(1,28)}=0.772 ; p>0.3\right)$ or genotype $\left(F_{(1,28)}=1.335 ; p>0.2\right)$, suggesting that the effect of the hippocampal lesion in GluR $\delta 2^{-/-}$mice was limited. The average temporal pattern of the EMG activity in the first postlesion session of the hippocampal-lesioned GluR $\delta 2^{-1-}$ mice also was similar to that of the control mutant mice (Fig. $4 F$ ). During the postlesion sessions, the CR\% of the hippocampal-lesioned GluR $\delta 2^{-/-}$mice (Fig. $4 D$ ) was unstable compared with the cortical-lesioned mice (Fig. 4C). A three-way repeated-measures ANOVA revealed that there was significant effect for both lesion type $\left(F_{(1,203)}=9.007 ; p<0.01\right)$ and genotype $\left(F_{(1,203)}=23.539\right.$; $p<0.001)$.

\section{The basic sensory and motor performances are normal}

To check for any possible effects of these lesions on the basic sensory or motor performance involved in eyeblink conditioning, we also looked at spontaneous eyeblink and startle responses to a tone. Spontaneous eyeblink frequency was not influenced by hippocampal destruction in either wild-type mice or GluR $\delta 2^{-1-}$ mice (Fig. 2). A two-way ANOVA indicated no significant interaction effects between genotype and lesion type $\left(F_{(1,28)}=0.005\right.$; $p>0.9)$ and no significant effects for genotype $\left(F_{(1,28)}=0.856\right.$; $p>0.3)$ or lesion type $\left(F_{(1,28)}=2.885 ; p=0.1\right)$. The frequency of the startle responses during conditioning was $5.5 \pm 0.6 \%(n=8)$ and $5.7 \pm 0.6 \%(n=7)$ for the cortical- and hippocampallesioned wild-type mice, respectively, and $5.7 \pm 0.5 \%(n=9)$ and $5.0 \pm 0.6 \%(n=8)$ for the cortical- and hippocampal-lesioned GluR $\delta 2^{-/-}$mice, respectively. The mean startle response of the hippocampal-lesion group was almost the same as that of the control group and did not increase during conditioning. There were no significant effects for genotype $\left(F_{(1,203)}=0.108 ; p>0.7\right)$, lesion type $\left(F_{(1,203)}=0.240 ; p>0.6\right)$, or session $\left(F_{(6,203)}=0.525\right.$; $p>0.7)$.

\section{Discussion}

In the present study, we demonstrated that ablation of the dorsal hippocampus severely impairs the acquisition of a $\mathrm{CR}$ in GluR $\delta 2^{-1-}$ mice. This result clearly indicates that eyeblink conditioning with a short trace interval in GluR $\delta 2^{-/-}$mice depends primarily on the hippocampus and mirrors the effect of scopolamine in GluR $\delta 2^{-I-}$ mice (Takatsuki et al., 2002), thus supporting the idea that the functional hippocampus is important to cerebellar LTD-independent learning to occur.

Previous studies using rabbits and rats have indicated that the hippocampus is required for eyeblink conditioning with a long trace interval but not with a shorter trace interval (Solomon et al., 1986; Moyer et al., 1990; Weiss et al., 1999) and therefore have paid no attention to the role of the hippocampus in short traceinterval conditioning. The present study has revealed that the hippocampal-lesioned GluR $\delta 2^{-/-}$mice have severe impairment in learning the trace 0 paradigm, but the hippocampal-lesioned wild-type mice do not. Thus, the contribution of the hippocampus to short trace interval conditioning becomes greater in GluR $\delta 2^{-1-}$ mice than that in the wild-type mice, suggesting that cerebellar LTD-independent learning occurs efficiently with a contribution of the hippocampus. Because GluR $\delta 2^{-/-}$mice exhibit severe learning impairment with a delay paradigm (Kishi- moto et al., 2001a,c), this kind of hippocampal function does not work well during delay conditioning.

When considering the role of the hippocampus in GluR $\delta 2^{-/-}$ mice, it is important to ask whether it is required for retention of the acquired memory. Because the acquired CR was retained fairly well after a hippocampal lesion, we conclude that the hippocampus is not required for retention and recall of the memory. In eyeblink conditioning with a long trace interval, the contribution of the hippocampus appears to be time limited: hippocampal ablation $1 \mathrm{~d}$ after learning impairs retention of a trace eyeblink $\mathrm{CR}$, but ablation has no effect if it occurs 4 weeks after learning in rabbits (Kim et al., 1995) and mice (Takehara et al., 2002). Consistent with these lesion studies, excitability increases in hippocampal pyramidal neurons remain for a limited period of time after learning (Moyer et al., 1996; Thompson et al., 1996). In the present study, the hippocampal lesion affected the preacquired $\mathrm{CR}$ in GluR $\delta 2^{-/-}$mice in a time-dependent manner; it did not impair the retention at all if made a few days after asymptotic level of learning but moderately impaired the acquired CR if made right after asymptotic level of learning. This is consistent with the previous reports (Kim et al., 1995; Takehara et al., 2002) in the sense that the role of hippocampus in retention or expression of the memory diminishes as time elapses. However, because the CR remained to some extent even if the lesion were made right after learning, there is a possibility that the role of the hippocampus in eyeblink conditioning with a short trace interval is a little different from that in long trace interval conditioning. Additional experiments using wild-type animals will be needed to test this hypothesis.

In conclusion, the present study has demonstrated that the hippocampus is important for the acquisition, but not for the retention, of a motor memory in GluR $\delta 2^{-1-}$ mice, which have deficiencies selective to the cerebellar cortex, including cerebellar LTD. These results suggest that the hippocampal component of the eyeblink conditioning task becomes dominant in the cerebellar LTD-independent learning. It remains to be clarified where that memory trace is formed and stored and what the role of the hippocampus is in cerebellar LTD-independent learning. Answering these questions should lead to a better understanding of the role of the hippocampus in eyeblink conditioning and may provide valuable information concerning the general mechanism of hippocampus-dependent learning.

\section{References}

Barnes CA (1988) Spatial learning and memory process: the search for their neurobiological mechanisms in the rat. Trends Neurosci 11:163-169.

Berger TW, Orr WB (1983) Hippocampectomy selectively disrupts discrimination reversal conditioning of the rabbit nictitating membrane response. Behav Brain Res 8:49-68.

Ito M (1989) Long-term depression. Annu Rev Neurosci 12:85-102.

Kaneko T, Thompson RF (1997) Disruption of trace conditioning of the nictitating membrane response in rabbits by central cholinergic blockade. Psychopharmacology 131:161-166.

Kashiwabuchi N, Ikeda K, Araki K, Hirano T, Shibuki K, Takayama C, Inoue Y, Kutsuwada T, Yagi T, Kang Y, Aizawa S, Mishina M (1995) Impairment of motor coordination, Purkinje cell synapse formation, and cerebellar long-term depression in GluR $\delta 2$ mutant mice. Cell 81:245-252.

Kim JJ, Thompson RF (1997) Cerebellar circuits and synaptic mechanisms involved in classical eyeblink conditioning. Trends Neurosci 20:177-181.

Kim JJ, Clark RE, Thompson RF (1995) Hippocampectomy impairs the memory of recently, but not remotely, acquired trace eyeblink conditioned responses. Behav Neurosci 109:195-203.

Kishimoto Y, Kawahara S, Suzuki M, Mori H, Mishina M, Kirino Y (2001a) Classical eyeblink conditioning in glutamate receptor subunit $\delta 2$ mutant mice is impaired in the delay paradigm but not in the trace paradigm. Eur J Neurosci 13:1249-1253. 
Kishimoto Y, Hirono M, Sugiyama T, Kawahara S, Nakao K, Kishio M, Katsuki M, Yoshioka T, Kirino Y (2001b) Impaired delay but normal trace eyeblink conditioning in PLC $\beta 4$ mutant mice. NeuroReport 12:2919-2922.

Kishimoto Y, Kawahara S, Fujimichi R, Mori H, Mishina M, Kirino Y (2001c) Impairment of eyeblink conditioning in GluR $\delta 2$ mutant mice depends on the temporal overlap between conditioned and unconditioned stimuli. Eur J Neurosci 14:1515-1521.

Kurihara H, Hashimoto K, Kano M, Takayama C, Sakimura K, Mishina M, Inoue Y, Watanabe M (1997) Impaired parallel fiber $\rightarrow$ Purkinje cell synapse stabilization during cerebellar development of mutant mice lacking the glutamate receptor $\delta 2$ subunit. J Neurosci 17:9613-9623.

Morris RG, Garrud P, Rawlins JN, O’Keefe J (1982) Place navigation impaired in rats with hippocampal lesion. Nature 297:681-683.

Moyer Jr JR, Deyo RA, Disterhoft JF (1990) Hippocampectomy disrupts trace eye-blink conditioning in rabbits. Behav Neurosci 104:243-252.

Moyer Jr JR, Thompson LT, Disterhoft JF (1996) Trace eyeblink conditioning increases CA1 excitability in a transient and learning-specific manner. J Neurosci 16:5536-5546.

Paxinos G, Franklin KBJ (2001) The mouse brain in stereotaxic coordinates. San Diego: Academic.

Solomon PR, Gottfried KE (1981) The septohippocampal cholinergic sys- tem and classical conditioning of the rabbit's nictitating membrane response. J Comp Physiol Psychol 95:322-330.

Solomon PR, Solomon SD, Vander Schaaf E, Perry HE (1983) Altered activity in the hippocampus is more detrimental to classical conditioning than removing the structure. Science 220:329-331.

Solomon PR, Vander Schaaf ER, Thompson RF, Weisz DJ (1986) Hippocampus and trace conditioning of the rabbit's classically conditioned nictitating membrane response. Behav Neurosci 100:729-744.

Takatsuki K, Kawahara S, Mori H, Mishina M, Kirino Y (2002) Scopolamine impairs eyeblink conditioning in cerebellar LTD-deficient mice. NeuroReport 13:159-162.

Takehara K, Kawahara S, Takatsuki K, Kirino Y (2002) Time-limited role of the hippocampus in the memory for trace eyeblink conditioning in mice. Brain Res 951:183-190.

Thompson LT, Moyer Jr JR, Disterhoft JF (1996) Transient changes in excitability of rabbit CA3 neurons with a time course appropriate to support memory consolidation. J Neurophysiol 76:1836-1849.

Thompson RF, Kim JJ (1996) Memory systems in the brain and localization of a memory. Proc Natl Acad Sci USA 93:13438-13444.

Weiss C, Bouwmeester H, Power JM, Disterhoft JF (1999) Hippocampal lesions prevent trace eyeblink conditioning in the freely moving rat. Behav Brain Res 99:123-132. 